\title{
Effects of the task complexity on the performance of a Coincidence Timing Task of people with Down syndrome
}

\author{
Giordano Marcio Gatinho Bonuzzi ${ }^{1,2 *}$, Umberto César Corrêa ${ }^{1}$, Gisele Ladik Antunes ${ }^{1}$, Carlos \\ Bandeira de Mello Monteiro ${ }^{3}$, Alaércio Perotti Júnior ${ }^{4,5}$, Andrea Michele Freudenheim ${ }^{1}$, \\ Camila Torriani-Pasin ${ }^{1}$
}

\begin{abstract}
With the present study, we aimed to investigate the task complexity effects on the performance of a coincidence timing task in individuals with Down syndrome. The experimental group was consisted by 26 subjects with Down syndrome, 20 years old $( \pm 5)$, and classified as mild or moderate in International Classification of Functioning and Health. Each participant in the experimental group was matched by in function of gender and age with a participant in a control group without Down syndrome. Both groups performed a coincident timing task, in which the participant had different levels of structural and functional complexity. Performance measure was derived from the consistency (absolute error), accuracy (variable error) and direction of response (constant error). Individuals with Down syndrome presented spatiotemporal organization impairments related to the difficulty in dealing with motor demand in order to interact with the perceptive demand. They also experienced difficulty in adapt to task complexity, causing performance error in the task. Individuals with Down syndrome have deficits in perceptive and space-time organization, and this phenomenon may be explained by the difficulty in integrating perceptive stimulus to motor actions with a high number of elements involved.

Keywords: Complexity, Coincidence Timing, Down syndrome
\end{abstract}

\section{INTRODUCTION}

In the past few years there has been an increase of researchers' interests in investigating how individuals with disabilities perform and acquire movements, including those with Down syndrome (DS) (Cabeza-Ruiz et al., 2011; Torriani-Pasin et al., 2013; Wuang, Chiang, Su, \& Wang, 2011). The main questions have frequently been raised on three points: whether such movements could be considered normal or abnormal (Mulvey, Ringenbach, \& Jung, 2011); explaining and understanding their underlying motor processes and mechanisms (Mendonca, Pereira, \& Fernhall, 2011), and; elaborating new practice schedules and therapies (Wuang et al., 2011).
It seems well documented that people with DS has serious implications on neurological, physiological, and biomechanical systems. These individuals have singularities in the performance of movement and tasks (Lam, Hodges, VirjiBabul, \& Latash, 2009; Lana-Elola, WatsonScales, Fisher, \& Tybulewicz, 2011). For example, it has been reported that individuals with DS need more time experiencing movements in order to acquire and improve motor skills, mainly because of lack of ability to make anticipatory adjustments, as well as kinematic adjustments to perform a determined task (Rihtman et al., 2010). Moreover, research has shown that individuals with DS demonstrate

\footnotetext{
Manuscript received at August 25 $5^{\text {th }}$ 2015; Accepted at November $1^{\text {st }} 2016$

${ }^{1}$ Escola de Educação Física e Esporte - Universidade de São Paulo, São Paulo, Brazil.

${ }^{2}$ Universidade Paulista - UNIP, São Paulo, Brazil.

${ }^{3}$ Escola deArtes, Ciências e Humanidades - Universidade de São Paulo, São Paulo, Brazil.

${ }^{4}$ Fundação Hermínio Ometto - UNIARARAS, Araras, Brazil.

${ }^{5}$ Faculdades Integradas Einstein de Limeira, Limeira, Brazil.

* Corresponding author: Avenida Professor Mello Moraes, 65 - Cidade Universitária, São Paulo - SP, 05508-030 E-mail: giordanomgb@gmail.com
} 
slowness in movement initiation and completion (Lam et al., 2009).

In this sense, alternative explanations have suggested that the cerebral hypoplasia present during the development of children with DS imply in a differentiated communication between the brain circuitries (Lana-Elola et al., 2011). The atypical patterns of brain organization could likely be responsible for many general cognitive characteristics that generate certain difficulty in perception, organization and motor response (Meegan, Maraj, Weeks, \& Chua, 2006; TorrianiPasin et al., 2013). Still, the movement characteristics of individuals with DS have also been attributed to structural peculiarities such as the brainstem, cerebellum' sizes (Millan Sanchez et al., 2012) and pro-oxidant status (Aguiar et al., 2008). With this reasoning, researches have also shown that individuals with DS present deficits in performing tasks with higher perceptual requirements, mainly those of temporal synchronization (Gimenez, Stefanoni, \& Farias, 2007; Torriani-Pasin et al., 2013).

The fact that people with DS have deficits in performing task with higher perceptual requirements is a relevant point, which may be considered by the professionals who plan intervention for them. However, previous studies addressing this issue used simple tasks, such as Gimenez and colleagues (2007) and TorrianiPasin and colleagues (2013). This issue restricts the generalization of data into complex tasks (Wulf \& Shea, 2002) because these simple tasks involve a few degrees of freedom (Schaefer \& Hengge, 2016) and lower cognitive requirements (Billing, 1980; Wulf \& Shea, 2002).

Complexity in Motor Behavior field has been investigated in two fronts, structural and functional dimensions (Corrêa et al., 2010). It can be addressed in relation to the different phases of information processing such as perceptual, decision, action, and feedback. Perceptual complexity is related to the fact that the task can vary with the number of stimuli, speed or duration of stimulus intensity and extent over which the stimulus may be conflicting or confusing. With regards to decision making, when the perceptual information is acquired, the performer must translate it into meaningful units (different combinations of the same stimulus can have different interpretations, meaning to compare this memory storage and select an appropriate response). Action complexity is dependent on the number of muscle actions, the amount of coordinated actions, the speed and accuracy required. Complexity is also related to the quality, accuracy and intensity of feedback, timing (immediate/delayed), conflicting information and the number of sensory organs involved (Billing, 1980; Wulf \& Shea, 2002).

Considering the previously mentioned motorperceptive characteristics of individuals with DS, how could a task with different levels of complexity impact on their performance in coincidence timing tasks? Therefore, our purpose was to investigate the effects of task complexity on the performance of motor skills in individuals with DS.

\section{Participants}

\section{METHOD}

The study included 26 individuals with DS for the experimental group, with an average age of 20 years ( \pm 5 years), both genders, who were participants in a rehabilitation center in the cities of Piracicaba and Limeira (Brazil).

For the sample characterization in the experimental group, we used the classification domains of the International Classification of Functioning, Disability and Health (ICF), according to the following areas: acquisition of basic skills and the functional learning of elementary, purposeful actions (d1550); acquisition of complex skills by learning integrated set actions to follow rules, sequence and coordinate their own movements (d1551); focus intentionally on a specific stimulus, filtering out distracting noises (d160); decision making by making a choice between options, with implementation of choice effects (d177); perform a simple task by preparing, initiating and organizing the time and space needed for this task (d2101); oral communication by receiving oral messages, understanding the literal and implied meanings of messages in oral language (d310).

The inclusion criteria were: presence of DS as a medical diagnosis, with classification as mild and moderate according to the ICF classification 
(Table 1), and to accept participation in the study by written consent from their parents or person responsible. The exclusion criteria were: presence of severe visual impairment or blindness, deafness, associated diseases which may affect the specific effects from DS on the performance, cognitive impairment that preclude the understanding and collaboration during the proposed activities.

Table 1.

Sample characterization of the experimental group.

\begin{tabular}{|c|c|c|c|c|c|c|c|c|}
\hline Group & ICF & d1550 & d1551 & $\mathrm{d} 160$ & d177 & $\mathrm{d} 2101$ & $\mathrm{~d} 310$ & Total \\
\hline \multirow{2}{*}{ ETG } & Mild & 4 & 5 & 5 & 5 & 5 & 5 & \multirow{2}{*}{8} \\
\hline & Moderate & 4 & 3 & 3 & 3 & 3 & 3 & \\
\hline \multirow{2}{*}{ MTG } & Mild & 9 & 5 & 9 & 7 & 7 & 4 & \multirow{2}{*}{9} \\
\hline & Moderate & 0 & 3 & 0 & 2 & 2 & 4 & \\
\hline \multirow{2}{*}{ DTG } & Mild & 7 & 6 & 4 & 4 & 4 & 3 & \multirow{2}{*}{9} \\
\hline & Moderate & 2 & 3 & 5 & 5 & 5 & 6 & \\
\hline
\end{tabular}

Legend: ICF (International Classification of Functioning, Disability and Health), ETG: easy task group; MTG: moderate task group; DTG: difficult task group.

The experimental group was matched by gender and age with the control group regarding the following criteria: healthy subjects, with no visual impairment, and who accepted to participate in the study. All participants from control group were recruited from schools, colleges and universities of the cities of Piracicaba and Limeira (Brazil).

This study was approved by the Scientific Merit and Ethics Committee of the Centro Universitário Hermínio Ometto - Uniararas by the Protocol 942/2010. Moreover, all participants provided their consent to participate in the study and their parents filled the consent form. All assessments for inclusion and exclusion criteria, as well as the ICF assessments were performed by an external examiner, not involved with the study, and with 10 years of academic experience with neurological patients and with the use of ICF in the rehabilitation center.

\section{Task and instrument}

A timing coincident device validated by Corrêa e Tani (2004) was used in our study (Figure 1). This apparatus enabled the execution of a complex task, composed of a sequence of arm movements carried out as a result of an external stimulus, or rather, a task with a perceptive and motor demand. The instrument enabled performance measurements related to the task goal, and to manipulate the task complexity in both condition disposition (functional complexity) and quantity (structural complexity) of components.

This was composed of: (a) one straight bar, measuring $200 \mathrm{~cm} \times 10 \mathrm{~cm} \times 10 \mathrm{~cm}$ with ninety light emitting diodes (LEDs) placed in line and separated $1 \mathrm{~cm}$ from one to another; (b) a $70 \mathrm{~cm}$ $\times 90 \mathrm{~cm} \times 6 \mathrm{~cm}$ wooden table, on which five response keys measuring $5 \mathrm{~cm} \times 15 \mathrm{~cm}$ were placed; (c) a $10 \mathrm{~cm} \times 20 \mathrm{~cm} \times 2 \mathrm{~cm}$ box with 5 diodes to inform the subject about the coincidenttiming error (feedback); (d) a computer with software that switched the diodes on and off in sequence at a constant speed, and which measures the error time in milliseconds.

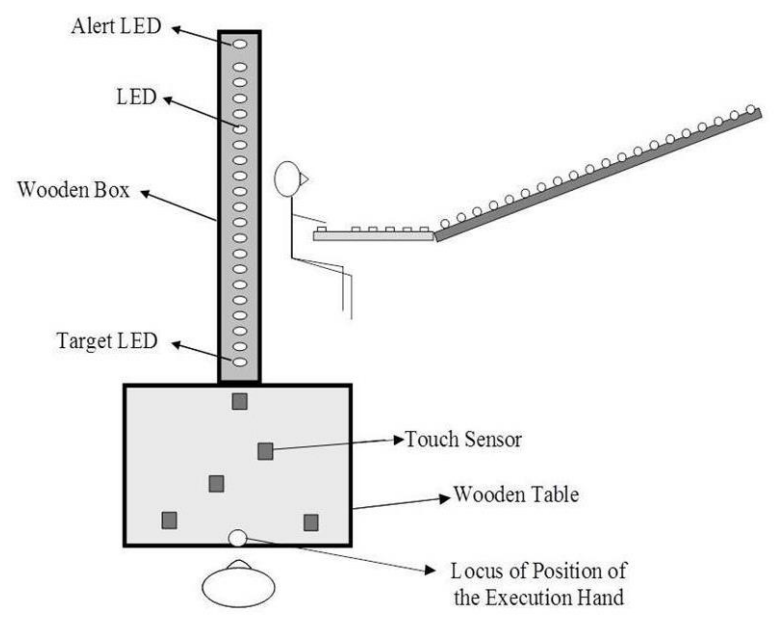

Figure 1. Coincident Timing Device

In sum, the task involved touching from one to five sensors in a sequence, according to the experimental condition, during the presentation 
of a visual stimulus - a sequence of LEDs lighting at a speed of $142.2 \mathrm{~cm} / \mathrm{sec}$ - in order that the last touch should coincide with the activation of a target LED. This speed was already used with people with DS in Torriani-Pasin et al. (2013).

\section{Procedures and design}

The participants of the experimental condition were randomly assigned into three groups of sensors disposition: (1) easy task group (ETG) or linear, (2) moderate task group (MTG) or with change of direction, and (3) difficult task group (DTG) or with change of direction and reversion. Each participant of the experimental group was paired with a participant of the control group.

Participants of all groups performed 15 trials divided in 5 blocks in which the participant performed three trials of touching 1, 2, 3, 4, and 5 sensors, always coinciding the last touch with the target diode. This number of trials was chosen in order to avoid the learning effects. The starting order in regards to the sensor quantity was counterbalanced between the participants to avoid sequence effects.

As illustrated in Figure 2, the ETG performed the task with the sensors arranged horizontally in a way the participant performed arm movements from left to right; for the MTG the sensors were arranged in a horizontal and vertical way involving angles of $90^{\circ}$. Thus, the participants performed arm movements from left to right and from back to front. Finally, the sensors arrangement of the DTG implied in a task with movements from left to right and backwards, and from front to back, in different angles.

The settings about structural and functional complexity used in the disposition of the sensors, as well as, the design of the experiment, were based on previous studies with healthy people, e.g. Corrêa and colleagues (2010).
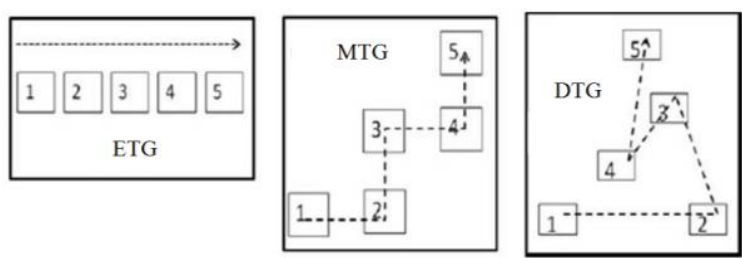

Figure 2. Disposition of the sensors according to the difficulty of the task. Legend: ETG: Easy Task Group;
MTG: Moderate Task Group; DTG: Difficult Task Group

The experiment followed the methodological protocol from previous studies which have used the coincident timing in complex tasks in healthy people (Corrêa et al., 2010) and individuals with DS (Torriani-Pasin et al, 2013). It was carried out in a $5 \times 4$ meter closed room. The experimenter received the participant and positioned them in front of the device, seated in an adjustable chair, so that their abdomen would be at the height of the table in order for them to touch all of the sensors freely. The participants were also tested to see whether they could touch the targets without stretching over the table. Once these aspects were considered, explanations regarding to the device and task were offered. After the explanations, the experimenter asked whether the participants understood the task, and then, the participants performed the task just one trial, in order to check their understanding about the task.

\section{Data analysis}

The data were analyzed in relation to precision, consistency and direction of coincident timing performance, respectively by absolute, variable and constant errors. Briefly, the absolute error is the mean of the errors in an absolute way; it represents the magnitude of the error (Schmidt \& Lee, 2011). Variable error is the standard deviation of this error and represent the variability of the performance (Schmidt \& Lee, 2011). Lastly, the constant error, represent the mean of the errors in an original way, that is, considered the negative or positive form; it represents the directions of this error and we can assess whether there was anticipation or delay (Schmidt \& Lee, 2011).

Movement pattern was analyzed by error of performance considering uncompleted trial or performed in a wrong sequence.

To consider the performance of participants on the tasks regarding different difficult levels, 2 x 3 x 5 mixed-model ANOVAs were conducted on data from the absolute, variable, and constant errors to identify main effects of Participants Characteristics (experimental and control) $\mathrm{x}$ 
Sensor Disposition (ETG, MTG and DTG) $\mathrm{x}$ Quantity of Touches (1, 2, 3, 4, and 5). Observed significant effects were followed up using TukeyнsD post-hoc tests. Concerning the data from the error of performance, the Kruskal-Wallis test was conducted to identify main effects of Sensor Disposition (ETG, MTG and DTG), and the Friedman ANOVA was run to identify main effects of Quantity of Touches (1, 2, 3, 4, and 5).
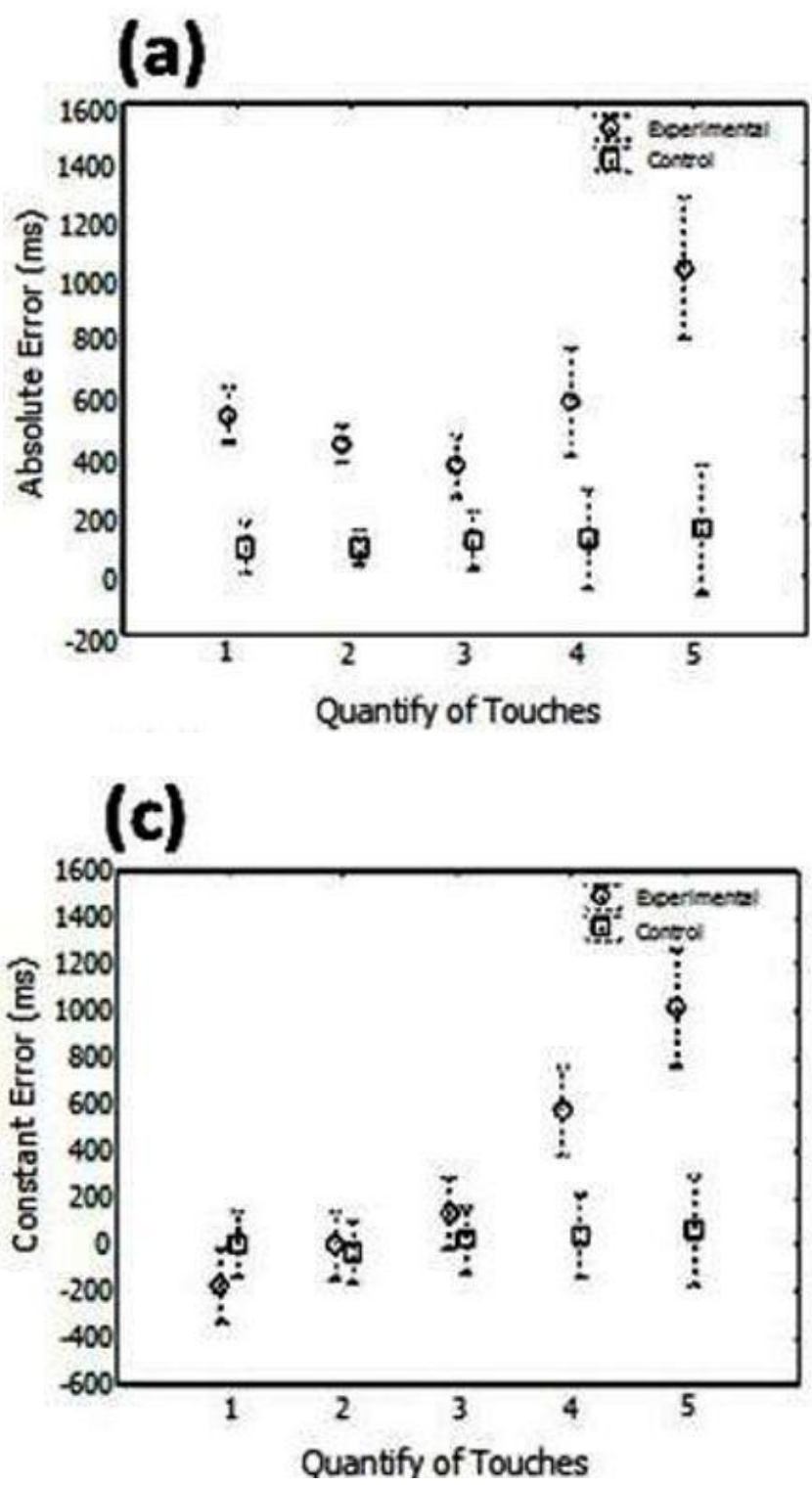

Figure 3. Graphs of each analysis conducted.

\section{RESULTS}

For absolute error, a $2 \times 3 \times 5$ mixed-model ANOVA (Participants Characteristics $\times$ Sensors Disposition $\times$ Quantity of Touches) revealed effects for Participants Characteristics $\left(F_{(1,40)}=\right.$ $\left.47.43 ; p<.01 ; \eta^{2}=.54\right)$, for Quantity of Touches $\left(F_{(4,160)}=12.00 ; p<.01 ; \eta^{2}=.23\right)$, and for
Observed significant effects were followed up using Mann-Whitney $U$ and Wilcoxon tests, respectively. All analyses were preceded by Shapiro-Wilk's W and Bartlett's tests of normality and homogeneity of variance. For all analyses, the level of significance was set at $p<$ .05 , using STATISTICA ${ }^{\circledR} 10.0$ software (Stat Soft Inc., Tulsa, USA).
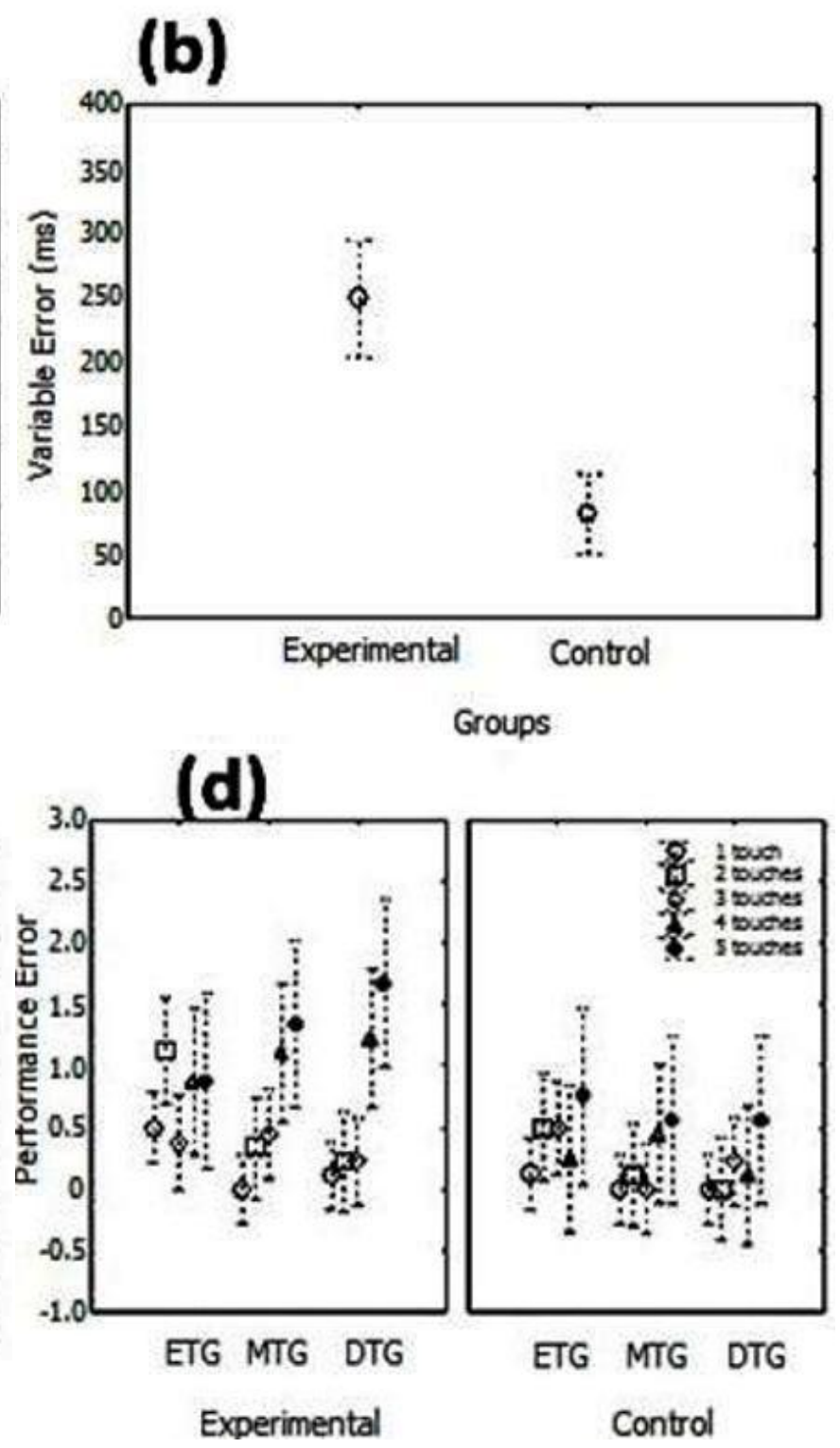

interaction between both $\left(F_{(4,160)}=8.63 ; p<.01\right.$; $\left.\eta^{2}=.18\right)$. It was observed that for the experimental group the absolute error in 5 touches was greater than those in the remain quantities of touches $(p<.01)$, and that this group had greater absolute error in 1, 2, 4, and 5 touches than control group $(p<.01)$ (Figure 3a). 
Concerning to the variable error, a $2 \times 3 \times 5$ mixed-model ANOVA (Participants Characteristics $\times$ Sensors Disposition $\times$ Quantity of Touches) revealed effects only for Participants Characteristics $\left(F_{(1,40)}=39.20 ; p<\right.$ $\left..01 ; \eta^{2}=.63\right)$. Post hoc testing showed that the experimental group had greater variable error than control group $(p<.01)$ (Figure 3b).

For constant error, a $2 \times 3 \times 5$ mixed-model ANOVA (Participants Characteristics $\times$ Sensors Disposition $\times$ Quantity of Touches) revealed effects for Participants Characteristics $\left(F_{(1,40)}=\right.$ 9.03; $p<.01 ; \eta^{2}=.18$ ), for Quantity of Touches $\left(F_{(4,160)}=34.87 ; p<.01 ; \eta^{2}=.47\right)$, and for interaction between both $\left(F_{(4,160)}=27.37 ; p<.01\right.$; $\left.\eta^{2}=.41\right)$. It was observed that in 4 and 5 touches the experimental group had the constant error greater than control group $(p<.01)$, which configures late motor response (Figure $3 c$ ).

Finally, in relation to the error of performance, Friedman test, it was revealed main effects for experimental group from MTG $\left(\chi^{2}[N=9\right.$; $\mathrm{df}=$ $4]=17.55 ; p<.01)$, and DTG $\left(\chi^{2}[N=9 ; \mathrm{df}=4]\right.$ $=18.24 ; p<.01)$ levels. Wilcoxon test showed that for the MTG the quantity of error of performance was greater in 4 and 5 touches than in 1,2 , and 3 touches $(p<.05)$; and, for the DTG the quantity of error of performance in 5 touches was greater than in 1,2 , and 3 touches $(p<.05)$ (Figure 3d).

\section{DISCUSSION}

The knowledge about motor control of the people who have neurological impairments or special needs is an important issue in Motor Behavior area. This knowledge allows the development of the most effective intervention techniques. In the DS cases, this background related to the motor control impairments can influences strategies for improve the Activities of Daily Living as well as the improve of quality of life (Mulvey et al., 2011). Regarding this background, the literature already have important findings about the DS effects on bimanual coordination (Mulvey et al., 2011), timing coincident capacity (Torriani-Pasin et al., 2013), motor learning synergies (Latash, 2007).

This study aimed to verify the task complexity effects on the performance of motor skills in DS individuals, more specifically in coincident timing tasks. The results allowed extending the comprehension of the performance of DS individuals in relation to spatio and temporal organization deficits and the difficulty of understanding the task.

Regarding the spatiotemporal organization deficit, people typically organize their reaching and aiming movements to achieve the precision dictated by the task demands, while optimizing movement speed and energy efficiency. When faced with unexpected changes to the task demands, they are usually quite adept at adjusting their movement trajectories to accommodate the new environmental constraints (Elliott et al., 2010). The individuals with DS presented difficult in dealing with several items (motor demand) in order to interact (perceptual coupling) with visual stimulus (perceptive demand). This statement is based on the results regarding that there were no effects for disposition sensors, but only for quantity of sensors. Moreover, the reaching performance of these individuals is marked on the follow aspects: 1 - greater error magnitude in five touches than in the remains quantities (absolute error), 2 inconsistency of performance, due the higher variability in the variable error, and 3 - tendency of performing late motor response in complex movements (constant error).

To this respect there is already some evidence in the literature that children with DS demonstrate impairments in perceptual-motor coupling. For example, when children with DS perform motor tasks requiring anticipatory actions (such as catching), their impairments appear to be attributable to difficulties in regulating the temporal aspects of their actions (Savelsbergh, de Jong, \& Ferguson-Hessler, 2000). The documented significant increase in the dwell time in subjects with DS, suggests insights into possible differences in the neural control processes in these subjects. Potentially, delayed time may be affected by both mechanical and neural factors (Lam et al., 2009) as hypotonia and reaction time.

In general, children with DS manifest delayed gross motor skills as a consequence of their hypotonia and ligamentous hyperlaxity 
(Visootsak et al., 2011). This condition make them to have more difficulty in adopting antigravitational postures and require more time to improve an acquired skill (Tudella, Pereira, Basso, \& Savelsbergh, 2011). Furthermore, DS people have difficulty in performing precision goal-directed movement, and they are typically slower to achieve the same degree of accuracy compared with young adults (Elliott et al., 2010).

Moreover, children with DS have difficulty in properly adjusting both the spatial and temporal aspects of their grasp as a function of object size or task goal (Costa, 2011). This suggests that children with DS maybe unable to use early visual cues about an obstacle and so wait until they reach an obstacle to extract the visual information needed to appropriately modulate their actions. The present result corroborates the findings of Costa (2011) and provides further evidence of difficulties in perceptual-motor coupling in DS regarding task complexity.

Our findings show that task complexity affects the understanding about nature of the task by people with DS. With respect to the difficulty of understanding about the nature of the task, even considering the fact that reaching movements are very usual in the Activity Daily Living (Kilbreath \& Heard, 2005), still they require some attention and processing demands to perform these tasks.

Therefore, people with DS encounter in their everyday life numerous tasks that require performing fast and accurate actions with their upper arm, such as catching objects or picking-up moving objects (Lam et al., 2009). To perform these motor functions, it is essential that the individual understands the needs and goals of the task, and maybe the complexity of the task will affect this comprehension.

Our results shows that SD people increased performance errors when the task was performed with touching in 4 and 5 sensors (MDG) and 5 sensors (DTG), than in those of touching 1,2 , and 3 sensors. These results could be explained by higher processing demands imposed by complex tasks (Corrêa \& de Souza, 2009), which are not compatible with the cognitive deficits from people with DS (Cabeza-Ruiz et al., 2011).

Individuals with intellectual disabilities have differences in information processing, which affect everyday skills, independence and social competence (Millan Sanchez et al., 2012). Although there has been enormous progress in care and treatment of the physical aspects of DS, little progress has been made to prevent deterioration of cognitive function in these individuals. As a result, the increase in life expectancy of children with DS in the past few decades has not been paralleled with the concurrent intervention for cognitive disabilities (Groen, Yasin, Laws, Barry, \& Bishop, 2008).

It seems that there are critical threshold values for task complexity effects on the performance of DS individuals. Our results could be explained by the major difference of movements performed by persons with DS and the different patterns of muscle activation they use to perform movements and to adjust them to changes in the environment (Latash, 2007). In comparison with people without disabilities, individuals with DS are significantly slower when performing a motor task, independently of the difficulty (Lam et al., 2009). Accordingly, the movement performed by the person with DS took twice as long to complete. This extended movement time is partly because of a lower peak in the magnitude of acceleration, but the primary reason for the extra time is associated with the multiple discontinuities in acceleration after peak velocity was achieved (Elliott et al., 2010).

These discontinuities are usually thought to reflect feedback-based corrections designed to reduce the degree of discrepancy between the position of the limb and the target (i.e., limbtarget control). Because these corrections are necessary, the assumption is that the performers with DS have problems with movement planning and feedforward control. Increasing task difficulty (index of difficulty) for persons with DS led to larger increments in movement time as compared to the typically developing group (Lam et al., 2009).

This study brings more insights to the design of practice tasks suggesting that intervention programs to this population may consider the task complexity, especially regarding the number of elements in a task. This information could be useful to plan appropriate progression into the intervention planning. However, it is important 
to consider the heterogeneity in the performance of the DS Group. Taking into account the characteristics of this population (i.e. nervous, anatomical, sensorial and cognitive aspects) it is difficult to create a homogeneous study group that presents less dispersion in the results, because the clinical conditions are multifactorial (Cabeza-Ruiz et al., 2011). Further investigations should consider the severity of DS as a function of task complexity and also analyse this phenomenon in different task-demand DS like reaching and grasping tasks.

Finally, these results must be applied carefully in intervention contexts. The limited number of participants and the task characteristics interfere in the generalization of data from this study. In fact, laboratory studies have important distinctions to naturalistic tasks or Activity of Daily Living (Ingram \& Wolpert, 2011; Wulf \& Shea, 2002). In everyday tasks, there are the occurrence of particular behaviours that are not required in laboratory analyses, such as: 1 physical interaction with objects, 2 - social interaction and 3 - specific cinematic and kinetic demands (Ingram \& Wolpert, 2011). Therefore, is still necessary to investigate the effects of the task complexity using more naturalistic approaches with a higher number of participants, especially in tasks involving more real life situation."

\section{CONCLUSION}

In summary, we concluded that individuals with DS present spatiotemporal organization deficit regarding the difficultly in dealing with the motor requirements of the task associated with the interaction with visual stimulus (perceptive demand). Additionally, task complexity presents difficulty for the individuals with DS in understanding the task, which caused error of performance in the task. Individuals with DS seem to have difficulties in performing coincident timing tasks with more than three elements.

\footnotetext{
Acknowledgements:

The authors acknowledge the participants of this study as well as the "Centro de Reabilitação Piracicaba" and "Associação de Reabilitação Infantil Limeirense".
}

\begin{tabular}{l}
\hline Conflict of Interests: \\
Nothing to declare. \\
\hline Funding: \\
This research was performed with support from \\
CAPES, organization of the Brazilian government for \\
developing scientific human resources.
\end{tabular}

\section{REFERENCES}

Aguiar, A. S., Tuon, T., Albuquerque, M. M., Rocha, G. S., Speck, A. E., Araújo, J. C., ... Pinho, R. A. (2008). The exercise redox paradigm in the Down's syndrome: Improvements in motor function and increases in blood oxidative status in young adults. Journal of Neural Transmission, $115(12)$, 1643-1650. http://doi.org/10.1007/s00702-008-0120-x

Billing, J. (1980). An overview of task complexity. Motor Skills Theory and Practice, 4, 18-23.

Cabeza-Ruiz, R., García-Massó, X., Centeno-Prada, R. A., Beas-Jiménez, J. D., Colado, J. C., \& González, L.-M. (2011). Time and frequency analysis of the static balance in young adults with Down syndrome. Gait \& Posture, 33(1), 23-28. http://doi.org/10.1016/j.gaitpost.2010.09.014

Corrêa, U. C., \& de Souza, O. P. J. (2009). Effects of goal difficulty and temporality in motor skill acquisition using the Bachman ladder. Perceptual and Motor Skills, 109(3), 817-823. http://doi.org/10.2466/pms.109.3.817-823

Corrêa, U. C., Massigli, M., Barros, J. A. D. C., Gonçalves, L. A., de Oliveira, J. A., \& Tani, G. (2010). Constant-random practice and the adaptive process in motor learning with varying amounts of constant practice. Perceptual and Motor Skills, 110(2), 442-452. http://doi.org/10.2466/PMS.110.2.442-452

Corrêa, U. C., \& Tani, G. (2004). Aparelho de timing coincidente em tarefas complexas. Revista Da Propriedade Industrial, 1763, 178.

Costa, A. C. S. (2011). On the Promise of Pharmacotherapies Targeted at Cognitive and Neurodegenerative Components of Down Syndrome. Developmental Neuroscience, 33(5), 414427. http://doi.org/10.1159/000330861

Elliott, D., Hansen, S., Grierson, L. E. M., Lyons, J., Bennett, S. J., \& Hayes, S. J. (2010). Goal-directed aiming: two components but multiple processes. Psychological Bulletin, 136(6), 1023-1044. http://doi.org/10.1037/a0020958

Gimenez, R., Stefanoni, F. F., \& Farias, P. B. (2007). Relação entre a capacidade de sincronização temporal e os padrões fundamentais de movimento rebater e receber em indivíduos com e sem síndrome de Down. Revista Brasileira Ciência E Movimento, 15(3), 95-101.

González-Agüero, A., Vicente-Rodríguez, G., GómezCabello, A., Ara, I., Moreno, L. A., \& Casajús, J. A. (2011). A combined training intervention 
programme increases lean mass in youths with Down syndrome. Research in Developmental Disabilities, $\quad 32(6)$, 2383-2388. http://doi.org/10.1016/j.ridd.2011.07.024

Groen, M. A., Yasin, I., Laws, G., Barry, J. G., \& Bishop, D. V. M. (2008). Weak hand preference in children with Down syndrome is associated with language deficits. Developmental Psychobiology, $50(3)$,

242-250. http://doi.org/10.1002/dev.20291

Ingram, J. N., \& Wolpert, D. M. (2011). Naturalistic approaches to sensorimotor control. Progress in Brain Research, 191, 3-29. http://doi.org/10.1016/B978-0-444-537522.00016-3

Kilbreath, S. L., \& Heard, R. C. (2005). Frequency of hand use in healthy older persons. Australian Journal of Physiotherapy, 51(2), 119-122. http://doi.org/10.1016/S0004-9514(05)70040-4

Lam, M. Y., Hodges, N. J., Virji-Babul, N., \& Latash, M. L. (2009). Evidence for slowing as a function of index of difficulty in young adults with down syndrome. American Journal on Intellectual and Developmental Disabilities, 114(6), 411-426. http://doi.org/10.1352/1944-7558-114.6.411

Lana-Elola, E., Watson-Scales, S. D., Fisher, E. M. C., \& Tybulewicz, V. L. J. (2011). Down syndrome: searching for the genetic culprits. Disease Models \& Mechanisms, 4(5), 586-595. http://doi.org/10.1242/dmm.008078

Latash, M. L. (2007). Learning motor synergies by persons with Down syndrome. Journal of Intellectual Disability Research, 51(12), 962-971. http://doi.org/10.1111/j.13652788.2007.01008.x

Meegan, S., Maraj, B. K. V, Weeks, D., \& Chua, R. (2006). Gross motor skill acquisition in adolescents with Down syndrome. Down's Syndrome, Research and Practice: The Journal of the Sarah Duffen Centre / University of Portsmouth, 9(3), 75-80.

Mendonca, G., Pereira, F., \& Fernhall, B. (2011). Effects of combined aerobic and resistance exercise training in adults with and without Down syndrome. Archives of Physical Medicine and Rehabilitation, 92(1), 37-45. http://doi.org/10.1016/j.apmr.2010.09.015

Millan Sanchez, M., Heyn, S. N., Das, D., Moghadam, S., Martin, K. J., \& Salehi, A. (2012). Neurobiological elements of cognitive dysfunction in down syndrome: Exploring the role of APP. Biological Psychiatry, 71 (5), 403-409. http://doi.org/10.1016/j.biopsych.2011.08.016

Mulvey, G. M., Ringenbach, S. D. R., \& Jung, M. L. (2011). Reversal of handedness effects on bimanual coordination in adults with Down syndrome. Journal of Intellectual Disability Research, 55(10), 998-1007. http://doi.org/10.1111/j.13652788.2011.01457.x

Rihtman, T., Tekuzener, E., Parush, S., Tenenbaum, A., Bachrach, S. J., \& Ornoy, A. (2010). Are the cognitive functions of children with Down syndrome related to their participation? Developmental Medicine \& Child Neurology, 52(1), 72-78. http://doi.org/10.1111/j.14698749.2009.03356.x

Savelsbergh, E. R., de Jong, T., \& Ferguson-Hessler, M. G. M. (2000). Learning physics with a computer algebra system. Journal of Computer Assisted Learning, 16(3), 229-242. http://doi.org/10.1046/j.13652729.2000.00135.x

Schaefer, S. Y., \& Hengge, C. R. (2016). Testing the concurrent validity of a naturalistic upper extremity reaching task. Experimental Brain Research, 234(1), 229-240. http://doi.org/10.1007/s00221-015-4454-y

Schmidt, R. A., \& Lee, T. D. (2011). Motor Control and Learning: A Behavioral Emphasis. (5th ed.). Champaign: Human Kinetics.

Torriani-Pasin, C., Bonuzzi, G. M., Soares, M. A., Antunes, G. L., Palma, G. C., Monteiro, C. B., ... Corrêa, U. C. (2013). Performance of Down syndrome subjects during a coincident timing task. International Archives of Medicine, 6(1), 15. http://doi.org/10.1186/1755-7682-6-15

Tudella, E., Pereira, K., Basso, R. P., \& Savelsbergh, G. J. P. (2011). Description of the motor development of 3-12 month old infants with Down syndrome: The influence of the postural body position. Research in Developmental Disabilities, $\quad 32(5), \quad$ 1514-1520. http://doi.org/10.1016/j.ridd.2011.01.046

Visootsak, J., Mahle, W. T., Kirshbom, P. M., Huddleston, L., Caron-Besch, M., Ransom, A., \& Sherman, S. L. (2011). Neurodevelopmental outcomes in children with Down syndrome and congenital heart defects. American Journal of Medical Genetics, Part A, 155(11), 2688-2691. http://doi.org/10.1002/ajmg.a.34252

Wuang, Y. P., Chiang, C. S., Su, C. Y., \& Wang, C. C. (2011). Effectiveness of virtual reality using Wii gaming technology in children with Down syndrome. Research in Developmental Disabilities, $32(1)$

312-321. http://doi.org/10.1016/j.ridd.2010.10.002

Wulf, G., \& Shea, C. H. (2002). Principles derived from the study of simple skills do not generalize to complex skill learning. Psychonomic Bulletin $\mathcal{E}$ Review, 9(2), 185-211. http://doi.org/10.3758/BF03196276 